\title{
On the Need for Cultural Sensitivity in Digital Wellbeing Tools and Messages: A UK-China comparison
}

\author{
John McAlaney ${ }^{1}$, Manal Aldhayan ${ }^{1}$, Mohamed Basel Almourad², Sainabou Cham ${ }^{1}$, \\ Raian $\mathrm{Ali}^{3}$ \\ ${ }^{1}$ Faculty of Science and Technology, Bournemouth University, UK \\ \{jmcalaney, maldhayan, scham\}@bournemouth.ac.uk \\ ${ }^{2}$ College of Technological Innovation, Zayed University, UAE \\ basel.almouradezu.ac.ae \\ ${ }^{3}$ Information and Computing Technology Division, College of Science and Engineering, \\ Hamad Bin Khalifa University, Qatar \\ raali2@hbku.edu.qa
}

\begin{abstract}
The excessive and obsessive use of the internet and digital technologies, known as Digital Addiction (DA), is becoming a social issue. Given that it inherently involves the use of technological devices this provides the opportunity to deliver interactive, intelligent prevention and intervention strategies in real-time. However, for any large-scale, multi-national prevention campaign to be optimised cultural differences within the target population must be considered. This study aimed to contribute towards this literature by exploring cultural differences in the acceptance of DA prevention messages in the UK vs China. An initial series of exploratory interviews were conducted with a sample within the UK to determine what strategies may be used to address the overuse of digital devices. These interviews were subjected to content analysis, which was then used as the basis for an online survey that was disseminated throughout the UK and China. A total of 373 useable surveys were returned. There were several statistically significant differences in preferences over how an intervention system should operate. UK participants wished for the system to be easily under their control, whilst behaving largely autonomously when needed, and to also be transparent as to why a message had been triggered. Chinese participants, on the other hand, were less likely to state a preference for such a high degree of control over any such system. Overall, the preferred implementation of such systems does appear to vary between the UK and China, suggesting that any future prevention and intervention strategies take cultural dimensions into consideration.
\end{abstract}

Keywords: Digital Addiction, Internet Addiction, Persuasive Messaging, Culture, Prevention.

\section{$1 \quad$ Introduction}

The excessive and obsessive use of the internet and digital technologies, known as Digital Addiction (DA), is becoming a social issue [1]. It has been suggested that DA is associated with a number of negative consequences, including poor academic per- 
formance, reduced social and recreational activities, relationships breakups, low involvement in real-life communities, poor parenting, depression and lack of sleep [2, 3]. Consistent with addiction it has also been argued that those experiencing DA can display symptoms of dependency and withdrawal such as depression, cravings, insomnia, and irritability [4]. It has been suggested that $6 \%-15 \%$ of the general population meet the requirement of DA [5], although these figures are dependent on varying definitions and conceptualisations of DA that exist between different countries. It has been argued that university and college students are at particular risk of DA [5]; with $18.3 \%$ of students in the UK identified as meeting the requirements of DA [6]. As such treatment and prevention approaches are needed.

In addition, there is a lack of research that considers the role of software developers in the phenomenon of DA, with some exceptions such as [7]. DA has unique characteristics in comparison to what could be considered traditional addictions. Given that it inherently involves the use of technological devices this provides the opportunity to deliver prevention and intervention strategies in real-time and whilst the targeted behaviour is occurring. This is not typically the case in behaviour change - in smoking, for example, people may see anti-smoking education campaign messages through a variety of mediums, but it would be difficult to ensure that these messages are seen while someone is in the act of smoking a cigarette.

Messages for DA can also be easily customised to the individual and to the social environment in which they operate. This has the potential to make prevention and intervention campaigns far more salient to the individual which, as based on social psychological research [8], could be expected to increase the efficacy of such campaigns. An important factor in the social environment of any individual will be culture. This is particularly relevant to DA, where the use of digital technologies and online platforms transcend national boundaries. As has been found in behaviour change campaigns conducted in other domains the success of an intervention is dependent on how well it is tailored to local, cultural and political contexts [9], although it has also been noted that this is still an under-researched area [10]. This article aims to begin work on addressing this gap by exploring attitudes towards DA interactive messaging with participants in the UK and China.

There is a substantial body of literature documenting and discussing cultural differences between the West and China. In particular, Hofstede's [11] research on cultural dimensions and Nisbett's research on cultural cognition [12] implies that messages presented to culturally different sets of users will attract different responses and interpretations. Nisbett's work indicates that Chinese people, users in the case of this paper, will tend to be much more holistic than UK users in how they perceive and process information, i.e. there will be a preference for understanding relations and how information makes sense as a whole. UK users instead will tend to be more analytical, breaking down the different information elements, trying to establish logical and causal relations wherever possible.

The UK and China differ significantly along two cultural dimensions, power distance and individualism [11]. China scores high in power distance as compared to the UK [13]. This means there will be more distance between figures of authority and those under them, and these differences are more likely to be accepted. Compared to the UK, China also scores low on individualism [13]. This indicates that China is a 
highly collectivist society and that the interests of the collective will be given priority to individual benefits.

Hofstede's cultural dimensions have been used to account for differences between how users respond to websites for countries with different levels of power distance and individualism, [14]. For a national culture like that of China, high in power distance and low on individualism, the tendency is to prefer content representing symbols of power or emerging from authority; any motivation should be aimed at the benefits of the collective and not only the individual. In contrast for a national culture like that of the UK, user interface content can be more informal and direct, accentuating the benefits for the individual.

Several authors have studied the effect of Asian and Western cultures on the use of interactive systems. For instance, Evers and Day [15] showed how Chinese, Indonesian and Australian users differed in perceived usefulness and ease of use towards the acceptance of a system; whereas Choi et al [16] demonstrated the value of culturespecific models and dimensions in the design of mobile data services by studying Finnish, Korean and Japanese users. Overall, the discussion of cultural effects on internet users' preferences is relevant to how users perceive DA messages and can provide insights on how to implement its use in culturally acceptable ways.

In this paper, we compare the perception of DA interactive and persuasive messages between users in China and UK. We reveal differences in the preferences towards both the content and the control over such interactive data-driven mechanisms towards behaviour change. As main technology companies have started to offer digital wellness and time management techniques, e.g. the Google Digital Wellbeing ${ }^{1}$ and Apple Screen Time ${ }^{2}$, which are meant to be used globally, our research highlights the importance of having cultural-sensitive design to maximise acceptance and user retention and avoid harmful experience users can have with these applications such as trivialisation of issues, creating an alternative source of preoccupation, over-trust and reactance [37].

\section{Method}

The methodology consisted of initial exploratory interviews stage followed by a survey. Screening items were used to ensure that the people who participated in the interviews and survey could be considered to demonstrate problematic levels of digital media use. These items were based on the first three items of the CAGE measure [17], which was developed as a tool to quickly screen for alcohol use disorders. The four items of the original measure ask individuals if they have ever felt they should i) cut down on their drinking, ii) been annoyed by people criticizing their drinking, iii) felt guilty about their drinking and iv) needed to drink in the morning to alleviate a hangover (eye-opener). For the purposes of this study 'drinking' was replaced by 'use of social networks or gaming' for the first three items. The fourth item of the original CAGE measure was not adapted for use as this was not relevant to the topic of digital addiction.

\footnotetext{
1 https://wellbeing.google/

2 https://support.apple.com/en-us/HT208982
} 
The initial exploratory stage consisted of interviews with 11 participants, five male and six female, aged between 19 and 35 years old. Four of them were professionals and seven were students. The interviews were to explore and understand how users see digital addiction messages. To ensure a range of views the sample included seven participants who liked the idea of messaging and four participants who did not feel messaging was an efficient idea. The interviews were recorded, and content analyzed and a set of statements on the messaging design, content, delivery and intelligence were obtained.

The second phase was based on an online survey. The purpose of the survey was to enhance and confirm the results obtained through the analysis of the interview. Our study in Ali, Jiang [18] reports the results of the interview analysis and confirmation with 72 participants who were mainly based in the UK and EU. To discover whether there could be cultural differences in the perception and preferences of DA messages, the survey was translated to Chinese and further disseminated in both its English and Chinese versions through mailing lists to students at a university, professional mailing lists and also the social media and mailing lists of the authors. A total of 373 usable surveys were returned, 151 from the UK (146 completed) and 222 from China (184 completed).

\section{Results}

There were 151 participants from the UK, which consisted of 81 females (54\%), 68 males $(45 \%)$ and 2 participants $(2 \%)$ who preferred not to declare their gender. There were 222 participants from China, which consisted of 117 females (53\%) and 103 males $(46 \%)$ and 2 participants who preferred not to declare their gender (1\%). Most participants in the UK (56\%) and China (62\%) were aged between $18-25$.

Most participants from both the UK and China (60\%) reported that they felt they sometimes felt they should cut down on their digital media use, including use of social networks or games.

As shown in Table 1, the most popular option for participants from both countries was messages based on the time already spent on the software, which participants from the UK were significantly more likely to agree to $\left(\chi^{2}=13.85, \mathrm{df}=1, \mathrm{p}<.001\right)$. UK participants were also more significantly more likely to agree that they would like messages that tell them the number of times they have checked/ visited the software $\left(\chi^{2}=18.1, \mathrm{df}=1, \mathrm{p}<.001\right)$, provided them the information in the form of a usage bill $\left(\chi^{2}=11.78, \mathrm{df}=1, \mathrm{p}=.001\right)$ or warned them about negative consequences to offline social life $\left(\chi^{2}=5.22\right.$, df $\left.=1, \mathrm{p}=.022\right)$. Participants from China, on the other hand, were significantly more to report that they would accept messages which suggest offline activities based on their online usage $\left(\chi^{2}=12.38\right.$, df $\left.=1, \mathrm{p}<.001\right)$.

Table 1. Percentage of participants in agreement that intervention message type would be useful (italics indicate statistically significant difference)

\begin{tabular}{|l|l|l|l|}
\hline Message type & $\begin{array}{l}\text { \% in } \\
\text { agreement }\end{array}$ & Message type & $\begin{array}{l}\% \text { in } \\
\text { agreement }\end{array}$ \\
\hline
\end{tabular}




\begin{tabular}{|l|l|l|l|l|l|}
\hline & UK & China & & UK & China \\
\hline $\begin{array}{l}\text { Time spent on apps/ } \\
\text { software }\end{array}$ & 77 & 59 & $\begin{array}{l}\text { Consequences for online } \\
\text { contacts }\end{array}$ & 14 & 22 \\
\hline Number of checks/visits & 51 & 29 & $\begin{array}{l}\text { Consequences on offline } \\
\text { social life }\end{array}$ & 35 & 24 \\
\hline $\begin{array}{l}\text { Heavily used features } \\
\text { and apps }\end{array}$ & 14 & 16 & $\begin{array}{l}\text { Physical/ mental health } \\
\text { risks }\end{array}$ & 48 & 47 \\
\hline $\begin{array}{l}\text { Potential risks of exces- } \\
\text { sive use }\end{array}$ & 26 & 32 & Risk of information & 26 & 18 \\
\hline Usage "bill" & 43 & 26 & $\begin{array}{l}\text { Advice on usage regula- } \\
\text { tion }\end{array}$ & 36 & 27 \\
\hline Public profile damage & 33 & 26 & $\begin{array}{l}\text { Suggestions of real-life } \\
\text { activities }\end{array}$ & 31 & 49 \\
\hline $\begin{array}{l}\text { Consequences on online } \\
\text { relationships }\end{array}$ & 21 & 20 & $\begin{array}{l}\text { Factual statements on the } \\
\text { benefits of regulation }\end{array}$ & 31 & 27 \\
\hline
\end{tabular}

Of the three most common preferences for the delivery of DA messages (Table 2), participants from the UK were significantly more likely to prefer each of these; namely pop-up notifications $\left(\chi^{2}=8.96, \mathrm{df}=1, \mathrm{p}=.003\right)$, time based progress statuses such as a clock display $\left(\chi^{2}=20.89, \mathrm{df}=1, \mathrm{p}<.001\right)$ and dynamic coloring of the interface $\left(\chi^{2}=5.77, \mathrm{df}=1, \mathrm{p}=.016\right)$. Participants from the UK were also significantly more likely to prefer messages delivered offline by for example email $\left(\chi^{2}=5.50, \mathrm{df}=1, \mathrm{p}=\right.$ .019 ), although overall this option was only preferred by a minority of participants.

Of the three most common preferences for the theme and source of warning messages overall (Table 2) participants from the UK were significantly more likely to prefer each of these; namely supportive content that is positive and encouraging $\left(\chi^{2}=\right.$ 11.16 , $\mathrm{df}=1, \mathrm{p}=.001)$, non-repetitive content $\left(\chi^{2}=8.43, \mathrm{df}=1, \mathrm{p}=.004\right)$, and nonoverly negative content $\left(\chi^{2}=22.24, \mathrm{df}=1, \mathrm{p}=<.001\right)$.

Table 2. Percentage of participants in agreement that different delivery types, themes and sources would be useful (italics indicate statistically significant difference)

\begin{tabular}{|c|c|c|c|c|c|}
\hline \multirow[t]{2}{*}{ Message delivery style } & \multicolumn{2}{|c|}{$\begin{array}{l}\% \text { in } \\
\text { agreement }\end{array}$} & \multirow[t]{2}{*}{$\begin{array}{l}\text { Theme and source of } \\
\text { the message }\end{array}$} & \multicolumn{2}{|c|}{$\begin{array}{l}\% \text { in } \\
\text { agreement }\end{array}$} \\
\hline & UK & China & & UK & China \\
\hline Pop-up notifications & 48 & 32 & $\begin{array}{l}\text { Positive and support- } \\
\text { ive content }\end{array}$ & 60 & 42 \\
\hline $\begin{array}{l}\text { Time based progress } \\
\text { status (e.g. clock) }\end{array}$ & 58 & 34 & Non-repetitive content & 48 & 34 \\
\hline $\begin{array}{l}\text { Dynamic colouring of the } \\
\text { interface }\end{array}$ & 45 & 33 & $\begin{array}{l}\text { Non-overly negative } \\
\text { content }\end{array}$ & 45 & 33 \\
\hline
\end{tabular}

Participants were asked to state how much they would like to be able to control different aspects of the intervention message software (Table 3). Compared to participants from China participants from the UK were significantly more likely to report that they would prefer to control the type of information contained in the message $\left(\chi^{2}\right.$ $=20.81, \mathrm{df}=1, \mathrm{p}<.001)$; the frequency with which messages are received $\left(\chi^{2}=\right.$ $11.68, \mathrm{df}=1, \mathrm{p}=.001)$; the presentation of the message in terms of graphics, sounds, 
emails etc $\left(\chi^{2}=12.58, \mathrm{df}=1, \mathrm{p}=<.001\right)$; what actions trigger the message $\left(\chi^{2}=\right.$ $13.15, \mathrm{df}=1, \mathrm{p}=<.001)$ and the source of the message in terms of software developers, institutions etc. $\left(\chi^{2}=19.01, \mathrm{df}=1, \mathrm{p}=<.001\right)$. Participants from the UK were also significantly more likely to report that they would like the software to act autonomously once it is set up $\left(\chi^{2}=4.92, \mathrm{df}=1, \mathrm{p}=.027\right)$. The only item which was reported as being significantly more desired by participants from China was having control over the strategy through which messages are generated, i.e. proactive or reactive to usage, or based on comparisons to others or an absolute scale $\left(\chi^{2}=4.28\right.$, df $=1, \mathrm{p}=.039$ ).

Table 3. Percentage of participants in agreement they would like control over different functions of the intervention software (italics indicate statistically significant difference)

\begin{tabular}{|l|l|l|l|l|l|}
\hline Control over function & \multicolumn{2}{|l|}{$\begin{array}{l}\text { \% in } \\
\text { agreement }\end{array}$} & \multicolumn{2}{l|}{$\begin{array}{l}\text { Control over func- } \\
\text { tion }\end{array}$} & \multicolumn{2}{|}{$\begin{array}{l}\text { \% in } \\
\text { agreement }\end{array}$} \\
\hline & UK & China & & UK & China \\
\hline Type of information & 41 & 19 & $\begin{array}{l}\text { Actions that trigger a } \\
\text { message }\end{array}$ & 38 & 21 \\
\hline Timing of messages & 39 & 21 & Source of the message & 29 & 11 \\
\hline Frequency of messages & 60 & 42 & $\begin{array}{l}\text { Strategy through } \\
\text { which messages are } \\
\text { triggered }\end{array}$ & 26 & 36 \\
\hline Message presentation style & 50 & 32 & $\begin{array}{l}\text { The degree to which } \\
\text { software is autono- } \\
\text { mous }\end{array}$ & 26 & 18 \\
\hline
\end{tabular}

\section{Discussion}

The majority of participants in both the UK and China stated that they sometimes felt they should cut down on their use of social networks or gaming. Given the use of the screening measure to identify those who appeared to use digital technologies excessively, this is not in itself surprising, but it does demonstrate that there is a demand for products which may aide people in better managing their use of digital technologies. This relates to the wider controversy on the status of DA as a mental health disorder. Following an extensive debate, DA was not included within the main body of the recently published Diagnostic and Statistical Manual (DSM-5) of the American Psychiatric Association [19], although it was included in the appendix as needing further research. More recently, in 2018, the World Health Organization has included Gaming Disorder within the International Classification of Diseases.

Most participants in both countries agreed that DA interactive messages would be useful, with participants from China significantly more likely to report this. Given that DA is an emergent phenomenon there is a lack of research into how DA messages should be created and delivered that the results of this study can be compared to. However, parallels can be drawn with research into cross-cultural differences in consumer psychology, which shares the same goal of marketing different products or ideas across different cultures [20]. The UK and China vary on a number of cultural 
dimensions, of which the most commonly researched is the individualist-collectivistframework [21]. Individualistic cultures are characterised by a focus on the success of the individual, whereas collectivist cultures focus more on the role of the individual into contributing to the wellbeing of the group. In support of this, individuals from the UK demonstrate characteristics of self-independence whereas individuals in China are more likely to display characteristics of interdependence and mutual reliance [22]. As further noted by Hofstede [23] individuals in a collectivistic culture such as China are more likely to adhere to a hierarchical structure, as well as being more sensitive to group membership [24].

The greater acceptance of participants from China towards the idea of warning messages is consistent with cross-cultural research in consumer psychology, which suggests that Chinese consumers place more emphasis on reputation than UK consumers [25]. Using anything to excess, including digital technologies, implies that the individual is in some way departing from the social norm of that group. As such, it could be expected that individuals in China would be more responsive to a system that warns them when their usage is becoming somehow excessive. However, it was also found that UK participants were significantly more likely to agree that they would like messages based on potential consequences to their offline social life, which is in contrast to what would be expected from the aforementioned research on the importance of group membership to those in a collectivistic culture.

Overall the significant differences between participants from the UK and China could be summarised as the UK participant expressing a wish for greater control and customisation of any potential DA messaging software. This is again consistent with cross-cultural research into consumer psychology, which has demonstrated that individuals from the UK like to be able to customise products [25]. In keeping with dual entitlement theory [26] people from individualistic cultures may, in fact, feel they are entitled to customisation, as this is what they have experienced in the past [25]. This finding is further reinforced by research on the relationship between locus of control and individualism as a cultural dimension. Locus of control is a social psychology concept that refers to how much individuals believe they are in control of events affecting them [27]. Spector, Cooper [28] demonstrate that individualistic cultures, like that of UK, will tend to reflect an internal locus of control, i.e. individuals expect to have control, while for collectivistic cultures like that of China an external locus of control is the case, i.e. individuals will expect not to have control. This could suggest that the ability to customize DA messaging is not just something which will increase the appeal of the software to UK users; such customization may in fact be necessary if users are to accept the software at all.

The effects of individualism-collectivism on website acceptability and usability have already been documented by several authors [14, 29, 30]. In this context, the findings reported here on the influence of individualism-collectivism on user preferences for DA messages are consistent with those of Cyr [29] who demonstrated how the cultural localization of websites for Canadian users (individualistic) and for a Chinese users (collectivistic) in terms of visual direction, information design and navigation design had a positive effect on satisfaction and trust towards content presented to them. 
Hofstede's survey and the resulting set of national culture models have been subject to criticism by various authors: McSweeney [31] considers the process to identify cultural dimensions through the analysis of differences in the survey as tautological and biased, e.g. only IBM employees took part. Kamppuri [32] refers to many instances where the expectations of Hofstede's cultural dimensions for particular sets of users were not met; Abufardeh and Magel [33] note that his survey was mainly developed from models of organisational culture while not exhaustively assessing national cultures. Overall, there is a general discussion around the applicability of national models to user interface design. As pointed by Kamppuri [32], this is seen as a contradiction: on one hand Hofstede encourages the application of his models and, on the other hand, he declares his model represents preferences underpinned by cultural values, which are more stable, and not cultural practices.

Whilst there were several statistically significant differences between the preferences of participants from the UK and China what is particularly interesting is the degree of overlap between countries. Even when differences were found it could be argued that most of these were not particularly substantive. Messages based on time spent on a platform or game appealed to most participants in both countries, which is a type of message that it would be relatively simple to generate for a number of software platforms. This wish for some kind of time-based message could relate to psychological research into the phenomena of being in a flow state [34], characterised as being 'in the zone', in which an individual may lose track of time whilst engaged with a social networking platform or whilst gaming [35]. Participants in both countries also expressed a desire for DA messages to be positive, supportive and to generally avoid being confrontational or negative. This dislike of individuals to being manipulated or coerced into behaving a certain way is known in social psychological research as reactance [36] and is important to consider when designing prevention and intervention campaigns.

In this paper, we argued the need for a culture-sensitive design of DA interactive messages which is a brief intervention mechanism towards a regulated and informed digital media usage. We investigated the differences between UK and Chinese users and demonstrated the existence of significant differences in the preferences and attitude towards such messages and their content, delivery method, autonomy, configuration and control. These results have implications for the development and conceptualization of technologies designed to address digital addiction, particularly in terms of how applicable and transferable these technologies are between cultures. However, culture is only one stage which may inform initial decisions about the viability and potential adoption of certain design options. The customisation of DA messages would require also a consideration of personal context as well as usage style and patterns. For example, messages requiring the sharing of usage statistics and sent by peers in a peer group setting may not be a preferred option for introvert users. Our future work will investigate the various variables which may influence the acceptance and right configuration of the DA messaging service to get the right behaviour change and avoid adverse effects. 


\section{Acknowledgements}

We thank Jingjie Jiang for helping in conducting the Chinese version of the survey. This study was partially funded by Zayed University through the SSCoDA project.

\section{References}

1. Moreno, M.A., et al., Problematic internet use among US youth: a systematic review. Arch Pediatr Adolesc Med, 2011. 165(9): p. 797-805.

2. Echeburua, E. and P. de Corral, Addiction to new technologies and to online social networking in young people: A new challenge. Adicciones, 2010. 22(2): p. 91-95.

3. Kuss, D.J. and M.D. Griffiths, Online social networking and addiction - A review of the psychological literature. International Journal of Environmental Research and Public Health, 2011. 8(9): p. 3528-3552.

4. Griffiths, M., The Psychology of Online Addictive Behaviour, in Cyberpsychology, A. Attrill, Editor. 2015, Oxford University Press: Oxford.

5. Young, K.S., X.D. Yue, and L. Ying, Prevalence estimates and etiologic models of internet addiction, in Internet Addiction: A Handbook and guide to evaluation and treatment, K.S. Young and C. Nabuco de Abreu, Editors. 2011, Wiley: Canada.

6. Kuss, D.J., M.D. Griffiths, and J.F. Binder, Internet addiction in students: Prevalence and risk factors. Computers in Human Behavior, 2013. 29(3): p. 959-966.

7. Ali, R., et al. The emerging requirement for digital addiction labels. in The 20th International Working Conference on Requirements Engineering: Foundation for Software Quality (REFSQ 2015). 2015. Essen, Germany.

8. Neighbors, C., M.E. Larimer, and M.A. Lewis, Targeting misperceptions of descriptive drinking norms: Efficacy of a computer delivered personalised normative feedback intervention. Journal of Consulting and Clinical Psychology, 2004. 72(3): p. 434 - 447.

9. Castro, F.G., M. Barrera, and C.R. Martinez, The cultural adaptation of prevention interventions: Resolving tensions between fidelity and fit. Prevention Science. 5(1): p. 41-45.

10. Beckfield, J., S. Olafsdottir, and B. Sosnaud, Healthcare systems in comparative perspective: Classification, convergence, institutions, inequalities, and five missed turns. Annual Review of Sociology, 2013. 39(1): p. 127-146.

11. Hofstede, G.H., G.J. Hofstede, and M. Minkov, Cultures And Organizations : Software Of The Mind : Intercultural Cooperation And Its Importance For Survival. 3rd ed. 2010, New York: McGraw-Hill. xiv, $561 \mathrm{p}$.

12. Nisbett, R., The geography of thought: How Asians and Westerners think differently... and why. 2010: Simon and Schuster.

13. Hofstede Insights. Compare countries. 2019 28/4/2019]; Available from: https://www.hofstede-insights.com/product/compare-countries/.

14. Marcus, A. and E. Gould, Crosscurrents: cultural dimensions and global web userinterface design. Interactions, 2000. 7(4): p. 32 - 46.

15. Evers, V. and D. Day, The role of culture in interface acceptance, in Human-Computer Interaction INTERACT '97: IFIP TC13 International Conference on Human-Computer Interaction, 14th-18th July 1997, Sydney, Australia, S. Howard, J. Hammond, and G. Lindgaard, Editors. 1997, Springer US: Boston, MA. p. 260-267.

16. Choi, B., I. Lee, and J. Kim, Culturability in mobile data services: A qualitative, study of the relationship between cultural characteristics and user-experience attributes. International Journal of Human-Computer Interaction, 2006. 20(3): p. 171-206. 
17. Ewing, J.A., Detecting alcoholism. The CAGE questionnaire. Jama, 1984. 252(14): p. 1905-7.

18. Ali, R., et al., The emerging requirement for digital addiction labels, in 2nd International Conference on Requirements Engineering: Foundations for Software Quality (REFSQ 15). 2015: Essen, Germany.

19. American Psychiatric Association, Diagnostic and statistical manual of mental disorders. 2013: Washington, DC.

20. Madden, T.J., M.S. Roth, and W.R. Dillon, Global Product Quality and Corporate Social Responsibility Perceptions: A Cross-National Study of Halo Effects. Journal of International Marketing, 2012. 20(1): p. 42-57.

21. Nijssen, E.J. and S.P. Douglas, Consumer World-Mindedness and Attitudes Toward Product Positioning in Advertising: An Examination of Global Versus Foreign Versus Local Positioning. Journal of International Marketing, 2011. 19(3): p. 113-133.

22. Chang, K. and L. Lu, Characteristics of organizational culture, stressors and wellbeing: The case of Taiwanese organizations. Journal of Managerial Psychology, 2007. 22(6): p. 549-568.

23. Hofstede, G., Culture's Consequences: International Differences in Work-Related Values. 1980, Newbury Park, CA: Sage Publications.

24. Hui, C.H., H.C. Triandis, and C. Yee, Cultural-differences in reward allocation - is collectivism the explanation. British Journal of Social Psychology, 1991. 30: p. 145-157.

25. Nguyen, B., K. Chang, and L. Simkin, Customer engagement planning emerging from the "individualist-collectivist"-framework: An empirical examination in China and UK. Marketing Intelligence \& Planning, 2014. 32(1): p. 41-65.

26. Kahneman, D., J.L. Knetsch, and R. Thaler, Fairness as a constraint on profit seeking entitlements in the market. American Economic Review, 1986. 76(4): p. 728-741.

27. Rotter, J.B., Generalized expectancies for internal versus external control of reinforcement. Psychological Monographs, 1966. 80(1): p. 1-\&.

28. Spector, P.E., et al., Locus of control and well-being at work: How generalizable are Western findings? The Academy of Management Journal, 2002. 45(2): p. 453-466.

29. Cyr, D., Modeling web site design across cultures: Relationships to trust, satisfaction, and e-loyalty. Journal of Management Information Systems, 2008. 24(4): p. 47-72.

30. Smith, A., et al., A process model for developing usable cross-cultural websites. Interacting with Computers, 2004. 16(1): p. 63-91.

31. McSweeney, B., Hofstede's model of national cultural differences and their consequences: A triumph of faith - a failure of analysis. Human Relations, 2002. 55(1): p. 89-118.

32. Kamppuri, M., Theoretical and methodological challenges of cross-cultural interaction design. 2011, University of Eastern Finland.

33. Abufardeh, S. and K. Magel. The impact of global software cultural and linguistic aspects on Global Software Development process (GSD): Issues and challenges. in New Trends in Information Science and Service Science (NISS), 2010 4th International Conference on. 2010.

34. Csikszentmihalyi, M., Flow : the psychology of optimal experience. 1st ed. 1990, New York: Harper \& Row. xii, 303 p.

35. Kaye, L.K., Exploring flow experiences in cooperative digital gaming contexts. Computers in Human Behavior, 2016. 55: p. 286-291.

36. Brehm, S. and J. Brehm, Psychological reactance: A theory of freedom and control. 1981, New York, NY: Academic Press. 
37. Alrobai, A., McAlaney, J., Phalp, K. and Ali, R., 2016. Exploring the Risk Factors of Interactive E-Health Interventions for Digital Addiction. International Journal of Sociotechnology and Knowledge Development (IJSKD), 8(2), pp.1-15. 